\author{
Quarterly Journal of Econometrics Research \\ 2022 Vol. 8, No. 1, pp. 1-10. \\ $\operatorname{ISSN}(e): 2411-0523$ \\ $\operatorname{ISSN}(p): 2518-2536$ \\ DOI: $10.18488 / 88 . v 8 i 1.2931$ \\ (C) 2022 Conscientia Beam. All Rights Reserved. \\ check for
updates
}

\title{
TREND ANALYSIS AND GARCH MODEL FOR COVID-19 NATIONAL WEEKLY CONFIRMED CASES IN NIGERIA FOR ABUJA AND LAGOS STATE
}

\author{
Lawal, O. O. ${ }^{1}$ \\ iD Nwakuya, M.T. ${ }^{2+}$ \\ Biu, O.E.
}

\author{
${ }^{\prime}$ Department of Mathematics/Statistics, Ignatius Ajuru University of \\ Education, Rivers State, Nigeria. \\ 'Email: miketedsnr@gmail.com Tel: +2348141152087 \\ ${ }^{2, s}$ Department of Mathematics and Statistics, University of Port Harcourt, \\ Rivers State, Nigeria. \\ ${ }^{2}$ Email:maureen.nwakuya@uniport.edu.ng Tel: +23408033167003 \\ ${ }^{3}$ Email:biu.emmanuel@uniport.edu.ng Tel: +2348038185228
}

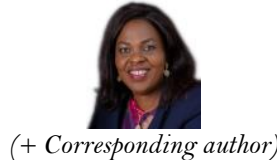

(+ Corresponding author

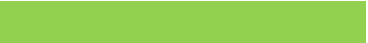

Article History

Received: 3 January 2022 Revised: 7 February 2022 Accepted: 18 February 2022 Published: 24 February 2022

Keywords:

Weekly COVID-19 confirmed

pandemic cases

Information criteria

Trend analysis models

GARCH models.

JEL Classification: C10; C50; C51; C01.

\begin{abstract}
The trend analysis and GARCH model for COVID-19 pandemic spread between FCT/Lagos and the National Weekly confirmed pandemic cases were carried out using the statistical software Minitab17 and Gretl. Four models trend behavior were considered, which are linear, quadratic, cubic and quartic trends with respect to $\mathrm{R}$ square value, Adjusted R-square value, Analysis of Variance (ANOVA) p-value and the estimated coefficients p-values. In addition, $\operatorname{GARCH}(0,1), \operatorname{GARCH}(1,0)$ and GARCH $(1,1)$ models were built separately for both FCT/Lagos on the Nigeria National Weekly confirmed pandemic cases; to determine which model has best fit for predicting weekly confirmed cases of COVID-19 pandemic in those areas. The four common information criteria was used to selected the best model, which are the Akaike Information Criteria (AIC), Schwarz-Bayesian Information Criteria (BIC), HannanQuinn Information Criteria (HQC) and Likelihood Criteria (LKH).This study established the quadratic trend and $\operatorname{GARCH}(1,0)$ as the best model that describes the data sets for FCT. Hence, both models can be used to forecasts the weekly pandemic confirmed cases in these areas.
\end{abstract}

Contribution/Originality: This work is one of the few that has tried to model COVID-19 weekly confirmed cases in Nigeria. The work has been able to establish that the quadratic trend with GARCH $(1,0)$ model was the best fit model for FCT and can be used to forecast weekly cases of COVID-19 in FCT Nigeria.

\section{INTRODUCTION}

The emergence of the COVID-19 disease has weakened the economy of many nations, caused confusion in communities and among the people, kept even the healthy people away from their usual or normal way of life. On the $27^{\text {th }}$ day of February, 2020, Nigeria recorded its first case of covid-19 according to Nigeria Center for Diseases Control on the $25^{\text {th }}$ of February. Generalized Autoregressive Conditional Heteroskedasticity (GARCH) is a statistical model used in analyzing time-series data where the variance error is believed to be serially autocorrelated. GARCH models assume that the variance of the error term follows an autoregressive moving average process.

The variance of the error term in GARCH models is assumed to vary systematically, conditional on the average size of the error terms in previous periods. In other words, it has conditional heteroskedasticity, and the reason for the heteroskedasticity is that the error term is following an autoregressive moving average pattern. This means 
that it is a function of an average of its own past values, like in trend analysis. Trend analysis attempts to predict future stock price movements based on recently observed trend data.

This work tries to determine the best fit model for predicting confirmed COVID-19 cases in Abuja and Lagos based on the National Weekly Confirmed cases (NWC) using GARCH Model. Furthermore, this research work seeks to establish the trend component in both Lagos and Abuja COVID-19 confirmed cases using trend analysis method. That is to show the effect of Lagos and Abuja COVID-19 confirmed cases on National Weekly Confirmed cases. The research will determine statistically, the area that contributes more to the national weekly confirmed cases.

\section{REVIEW OF LITERATURE}

Abdulmajeed, Adeleke, and Popoola (2020) in their article titled "Online Forecasting of covid-19 cases in Nigeria using limited data”, investigated the extent of the spread and effectiveness of containment strategies to stem the transmission of the disease. The combination of Autoregressive Integrated Moving Average (ARIMA) and a Hot-Winters Exponential Smoothing models combined with Generalized Autoregressive Conditional Heteroskedasticity $(\mathrm{GARCH})$ was employed. They concluded that it would be difficult to model covid-19 in the real-life scenario as inherent modeling difficulties, such as the number of tests, randomness and other factors contributed to the forecast model. Onafeso et al. (2021), conducted a research on Geographical Trend Analysis of covid-19 Pandemic onset in Africa. The method of Analysis of Variance (ANOVA) was used to show that significant variations exist among African countries in the number of covid-19 confirmed cases. Awan and Aslam (2020) predicted daily covid-19 cases in European countries using Automatic Autoregressive Integrated Moving Average (ARIMA) model. Malki et al. (2021) carried out a research on ARIMA models for predicting the end of COVID-19 pandemic and the risk of second rebound. The research work was necessary so that the questions of whether or not the virus will return can be answered. In this work, a predictive model that can estimate the expected period that the virus can be stopped and the risk of the second rebound of COVID-19 pandemic. Rauf and Oladipo (2020) did a work on Forecasting the spread of COVID-19 in Nigeria using Box-Jenkins Modeling Procedure. This study focused on the analysis of the spread of Covid-19 in Nigeria, applying statistical models and available data from the NCDC. They presented an insight into the spread of Covid-19 in Nigeria in order to establish a suitable prediction model, which can be applied as a decision-supportive tool for assigning health interventions and mitigating the spread of the Covid-19 infection. Aronu, Ekwueme, Sol-Akubude, and Okafor (2021) carried out an investigation on Coronavirus (Covid-19) in Nigeria: They examined the survival rate of Covid-19 patients in Nigeria using the Autoregressive Integrated Moving Average (ARIMA) forecasting approach. Odukoya et al. (2020), conducted a research on Epidemiological Trends of Coronavirus Disease 2019 in Nigeria: From 1 to 10,000. A secondary data collected from Nigeria Centre for Disease Control (NCDC) was used and the method of line graphs was adopted to describe the data of the daily recorded cases of covid-19 in Nigeria. They discovered that the epidemic curve in Nigeria has been on an upward trajectory as the number of cases crossed the 10,000 mark.

\section{METHODOLOGY}

This study design is focused on Trend Analysis and GARCH Model of Covid-19 cases between the National Weekly Confirmed cases (NWC) in Lagos and Federal Capital Territory (Abuja). The data for this study is a secondary data extracted from the website of the National Centre for Disease Control (NCDC) on the daily confirmed cases of covid-19 in Nigeria. The daily and weekly reported and confirmed cases from March $16^{\text {th }}, 2020$ to May $9^{\text {th }}, 2021$. The Gretl statistical software and Minitab were used for the analyses.

\subsection{Model Specification}

$\operatorname{GARCH}(1,1)$ is represented as; 


$$
Y_{t}=\boldsymbol{\mu}+\varepsilon_{t}
$$

where $\varepsilon_{t} \sim\left(0, \sigma_{t}^{2}\right)$

$$
\sigma_{t}^{2}=\omega+\alpha_{1} \varepsilon_{t-1}^{2}+\beta_{1} \sigma_{t-1}^{2}
$$

Equation 1 represents the GARCH model and Equation 2 presents the variance of the error at time $t$ where,

$\boldsymbol{\mu}$ is the mean.

$\sigma_{t}^{2}$ is that variance of the error at time t.

$\varepsilon_{i-1}^{2}$ is the squared error at time t- 1 .

Under the assumption that $\alpha+\beta<1, \frac{\omega}{1-\alpha-\beta}$ is the unconditional variance of $\mathrm{Y}_{\mathrm{i}}$.

$\omega$ constant coefficient.

$\alpha_{1}$ is the first (lag 1) ARCH Parameter.

$\beta_{1}$ is the (lag 1) GARCH parameter.

Estimation of GARCH model:

The popular GARCH $(1,1)$ model is defined by Equation $1 \& 2$.

For $\sigma_{t}^{2}$ to be non-negative, we require all the coefficients to be non-negative.

Using the definition $\sigma_{t}^{2}=\varepsilon_{t}^{2}+v_{t}$, we have,

$\sigma_{t}^{2}=\omega+\alpha_{1} \varepsilon_{t-1}^{2}+\beta_{1} \sigma_{t-1}^{2}$

$\varepsilon_{t}^{2}-v_{t}=\omega+\alpha_{1} \varepsilon_{t-1}^{2}+\beta_{1}\left(\varepsilon_{t-1}^{2}-v_{t-1}\right)$

$\varepsilon_{t}^{2}=\omega+\left(\alpha_{1}+\beta_{1}\right) \varepsilon_{t-1}^{2}+v_{t^{-}} \beta_{1} v_{t-1}$

The GARCH model is equivalent to an infinite ARCH model.

Where $\alpha_{0} \geq 0$ and $\alpha_{i} \geq 0, \mathrm{i}=1, \ldots, \mathrm{q}, \beta_{j} \geq 0, \mathrm{j}=1, \ldots \mathrm{p}$. The GARCH model built in the research are GARCH models with independent variable (the state weekly confirmed cases), given as:

$$
\begin{aligned}
& \text { GARCH }(1,1) \text { model: } \sigma_{t}^{2}=\omega+\alpha_{1} \varepsilon_{t-1}^{2}+\beta_{1} \sigma_{t-1}^{2}+\lambda_{1} X_{i} \\
& \operatorname{GARCH}(1,0) \text { model: } \sigma_{t}^{2}=\omega+\beta_{1} \sigma_{t-1}^{2}+\lambda_{1} X_{i}
\end{aligned}
$$

$\operatorname{GARCH}(0,1)$ model: $\sigma_{t}^{2}=\omega+\alpha_{1} \varepsilon_{t-1}^{2}+\lambda_{1} X_{i}$

Equation 3 represents GARCH $(1,1)$ model, Equation 4 represents GARCH $(1,0)$ model, and Equation 5 represents $\operatorname{GARCH}(0,1)$ model, where $\lambda_{1}$ is coefficient of independent variable, $X_{i}$ is the independent variable and $\omega$ is the constant coefficient. Test of Heteroskedasticity and stationarity were carried out before proceeding. The approach with the Linear Model test is to use the Ordinary Least Square method to estimate the most appropriate regression equation; we run a linear regression equation to obtain the residual. The regression equation can be an autoregressive (AR) process, moving average (MA) process or a combination of AR and MA process (ARMA) depending on the adequacy of the researcher model. For example, suppose we have a return series variable $y_{t}$, we can have an $\mathrm{AR}(1)$ regression equation as:

$$
y_{t}=\beta_{0}+\beta_{1} y_{t-1}+e_{t}
$$

Equation 6 is an Autoregressive model with 1 lag.

\subsubsection{Trend Analysis}

Trend analysis done for the linear trend model:

$$
\begin{aligned}
& \mathrm{Y}_{t}=C_{0}+C_{1} W_{t} \\
& \mathrm{Y}_{t}=C_{0}+C_{1} X_{t}
\end{aligned}
$$


Equation $7 \mathrm{a}$ and $7 \mathrm{~b}$ represent the trend models for FCT and Lagos state in Nigeria, where Y is dependent variable (NNWC), $W_{t}$ is independent variable for FCT Covid-19 Cases and $X_{t}$ is independent variable for Lagos Covid-19 Cases.

In this model, $C_{i}$ are the coefficients, representing the average change from one period to the next.

The quadratic trend model which can account for simple curvature in the data, is:

$$
\begin{aligned}
& \mathrm{Y}_{t}=C_{0}+C_{1} W_{t}+C_{2} W_{t}^{2} \\
& \mathrm{Y}_{t}=C_{0}+C_{1} X_{t}+C_{2} X_{t}^{2}
\end{aligned}
$$

The cubic trend model

$$
\begin{aligned}
& \mathrm{Y}_{t}=C_{0}+C_{1} W_{t}+C_{2} W_{t}^{2}+C_{3} W_{t}^{3} \\
& \mathrm{Y}_{t}=C_{0}+C_{1} X_{t}+C_{2} X_{t}^{2}+C_{3} X_{t}^{3}
\end{aligned}
$$

The quartic trend model

$$
\begin{aligned}
& \mathrm{Y}_{t}=C_{0}+C_{1} W_{t}+C_{2} W_{t}^{2}+C_{3} W_{t}^{3}+C_{4} W_{t}^{4} \\
& \mathrm{Y}_{t}=C_{0}+C_{1} X_{t}+C_{2} X_{t}^{2}+C_{3} X_{t}^{3}+C_{4} X_{t}^{4}
\end{aligned}
$$

Equations $8 \mathrm{a} \ldots 10 \mathrm{~b}$ represents the quadratic trend model, cubic trend model and quartic trend model, with $\mathrm{C}_{\mathrm{i}}$ as the coefficients of the model, W represents FCT and X represents Lagos state.

\subsubsection{Models Selection Criteria}

The three selection models criteria applied were the Akaike Information Criteria (AIC), Schwarz-Bayesian Information Criteria (BIC), and Hannan-Quinn Information Criteria.

\section{RESULTS}

The descriptive statistics of the Covid-19 Pandemic in the Nigeria National Weekly Confirmed cases (NNWC); Lagos and Federal Capital Territory (Abuja) COVID-19 Cases in Table 1.

Table 1. Statistics of Covid-19 pandemic in the Nigeria.

\begin{tabular}{l|c|c|c|c|c|c|c|c|c|c}
\hline Variable & Mean & $\begin{array}{c}\text { SE } \\
\text { Mean }\end{array}$ & $\begin{array}{c}\text { St. } \\
\text { Dev }\end{array}$ & Minimum & Q1 & Median & Q3 & Maximum & Skewness & Kurtosis \\
\hline LAGOS(x) & 980 & 142 & 1099 & 57 & 297 & 623 & 1281 & 4780 & 2.27 & 5.01 \\
\hline FCT (w) & 335 & 51.4 & 398.5 & 7 & 71.3 & 148.5 & 449 & 1727 & 1.76 & 2.42 \\
\hline NNWC (y) & 2792 & 353 & 2738 & 81 & 976 & 1703 & 3956 & 11179 & 1.55 & 1.89 \\
\hline
\end{tabular}

Table 1 shows the mean of the Covid-19 Pandemic in Nigeria, where the expected value is 980 cases for Lagos area, 335 for FCT and 2792 for National Weekly Confirmed cases.

\subsection{Trend Analysis}

The trends of the Covid-19 Pandemic of the two densely populated areas in Nigeria against the National weekly confirmed cases were identified below in Table 2 and in the plots; Figures 1 to 8 . The fitted trends are linear, quadratic, cubic and quartic (or polynomial of order four) with their R-squares. 
The results in Table 2 and Figures 1-4 identified that the quadratic trend is the best trend among the trend curves to describe Covid-19 Pandemic in FCT against the National weekly confirmed cases. The R-square value indicates that the predictors explain $87.41 \%$ of the variance of the Covid-19 Pandemic. This suggests that a quadratic trend or order two polynomial is more appropriate. The quadratic trend does not appear to be overfit and has adequate predictive ability. The identified trend is:

$$
\mathrm{Y}_{t}=C_{0}+C_{1} W_{t}+C_{2} W_{t}^{2}=80.25+11.32 W_{t}-\left(4.03 \times 10^{-3}\right) W_{t}^{2}
$$

Table 2. Trend analysis of NNWC (y) against FCT (w).

\begin{tabular}{|c|c|c|c|c|}
\hline Coefficients & Linear & Quadratic & Cubic & Quartic \\
\hline$\beta_{0}$ & $818.24\left(0.001^{* *}\right)$ & $80.25(0.771)$ & $453.79(0.171)$ & $146.93(0.724)$ \\
\hline$\beta_{1}$ & $5.89\left(0.000^{* *}\right)$ & $11.32(0.000)^{* * *}$ & $7.03(0.007)^{* *}$ & $12.49(0.020)^{* * *}$ \\
\hline$\beta_{2}$ & & $-4.03 \times 10^{-3}(0.000)^{* *}$ & $3.70 \times 10^{-3}(0.361)$ & $-1.48 \times 10^{-2}(0.356)$ \\
\hline$\beta_{3}$ & & & $-3.37 \times 10^{-6}(0.053)$ & $1.56 \times 10^{-5}(0.331)$ \\
\hline$\beta_{4}$ & & & & $-5.82 \times 10^{-09}(0.235)$ \\
\hline$R^{2}$ & $73.4 \%$ & $87.41 \%$ & $81.1 \%$ & $81.6 \%$ \\
\hline $\bar{R}^{2}$ & $72.9 \%$ & $85.90 \%$ & $80.1 \%$ & $80.3 \%$ \\
\hline Analysis of Variance & $\begin{array}{lr}\text { Source } & \text { P-Value } \\
\text { Regression } & 0.000^{* *} \\
\text { FCT (w) } & 0.000^{* *}\end{array}$ & $\begin{array}{lc}\text { Source } & \text { P-Value } \\
\text { Regression } & 0.000^{* *} \\
\text { FCT }(\mathrm{w}) & 0.000^{* *} \\
\mathrm{w}^{2} & 0.000^{* *}\end{array}$ & $\begin{array}{ll}\text { Source } & \text { P-Value } \\
\text { Regression } & 0.000^{*} * \\
\text { FCT }(\mathrm{w}) & 0.007^{* *} \\
\mathrm{w}^{2} & 0.361 \\
\mathrm{w}^{3} & 0.053\end{array}$ & $\begin{array}{ll}\text { Source } & \text { P-Value } \\
\text { Regression } & 0.000^{* *} \\
\text { FCT }(\mathrm{w}) & 0.020^{* *} \\
\mathrm{w}^{2} & 0.356 \\
\mathrm{w}^{3} & 0.331 \\
\mathrm{w}^{4} & 0.235\end{array}$ \\
\hline
\end{tabular}

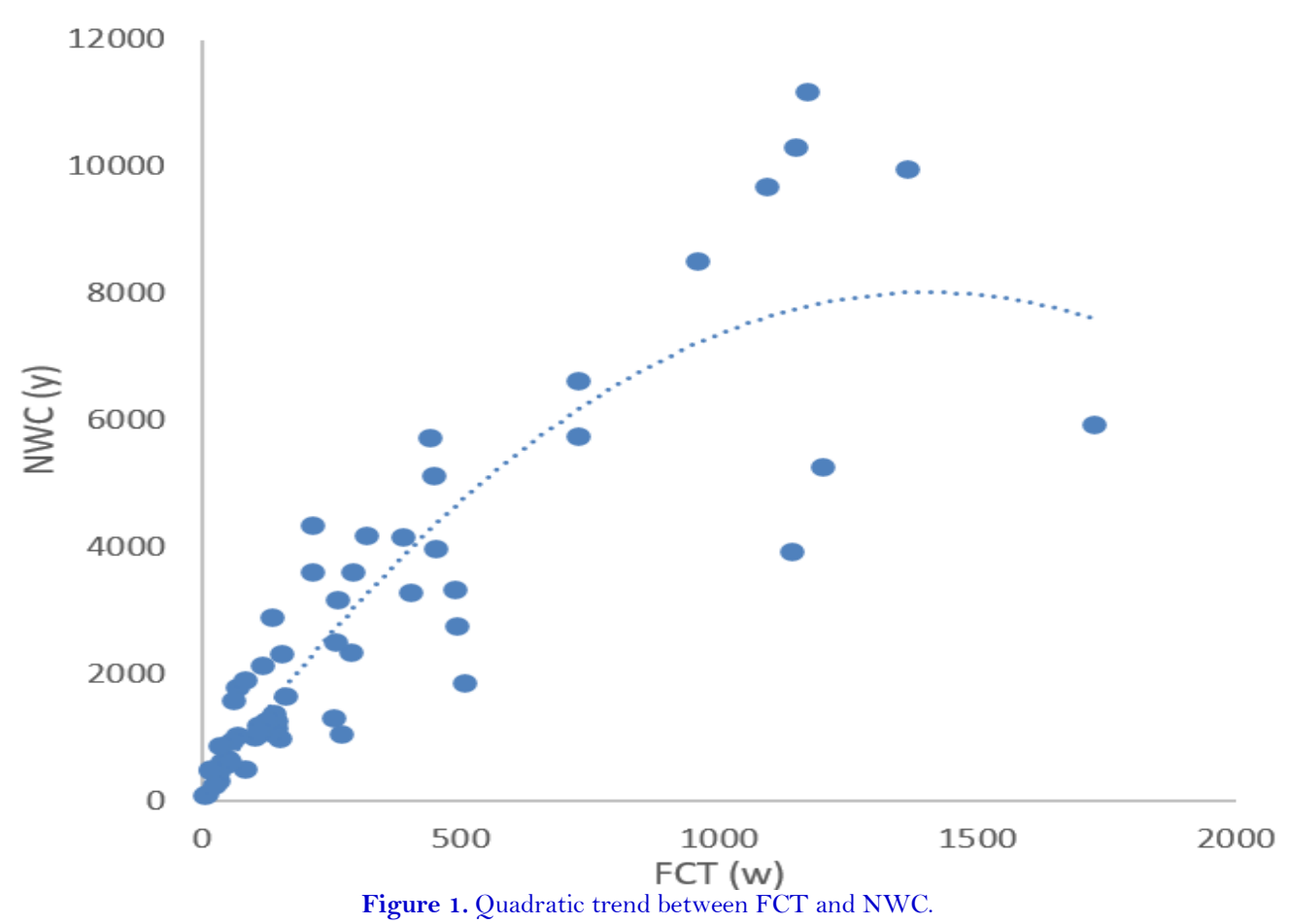




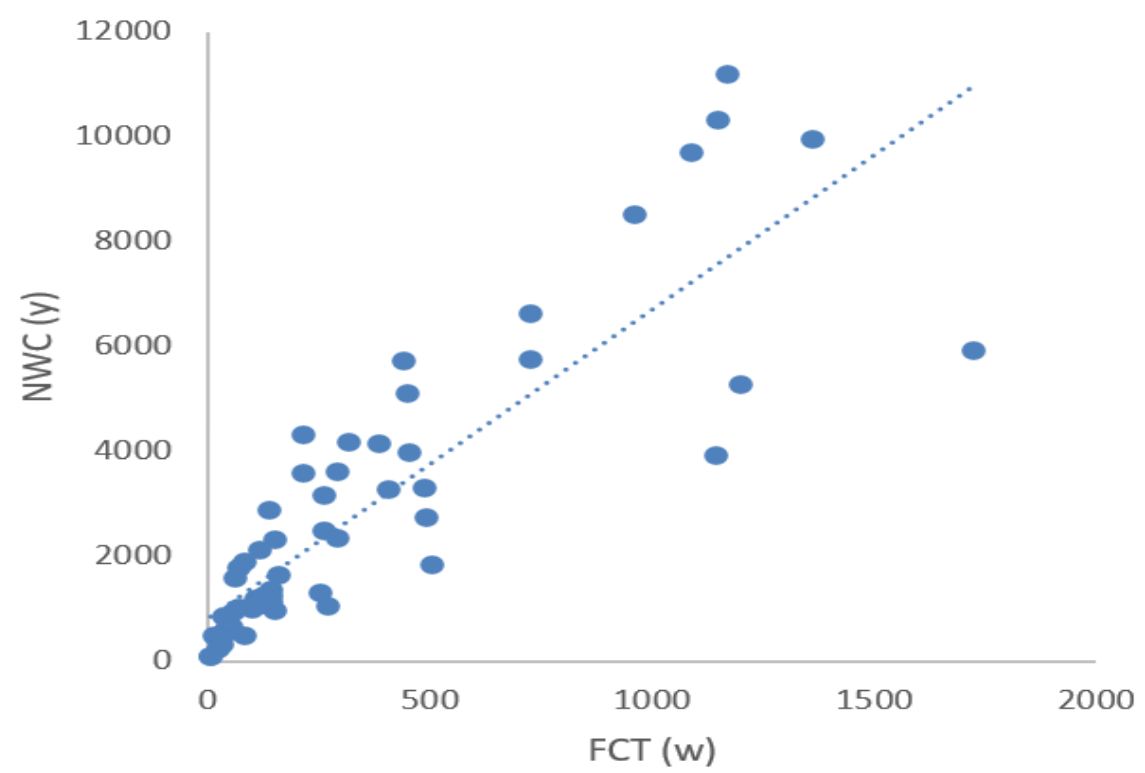

Figure 2. Linear trend between FCT and NWC.

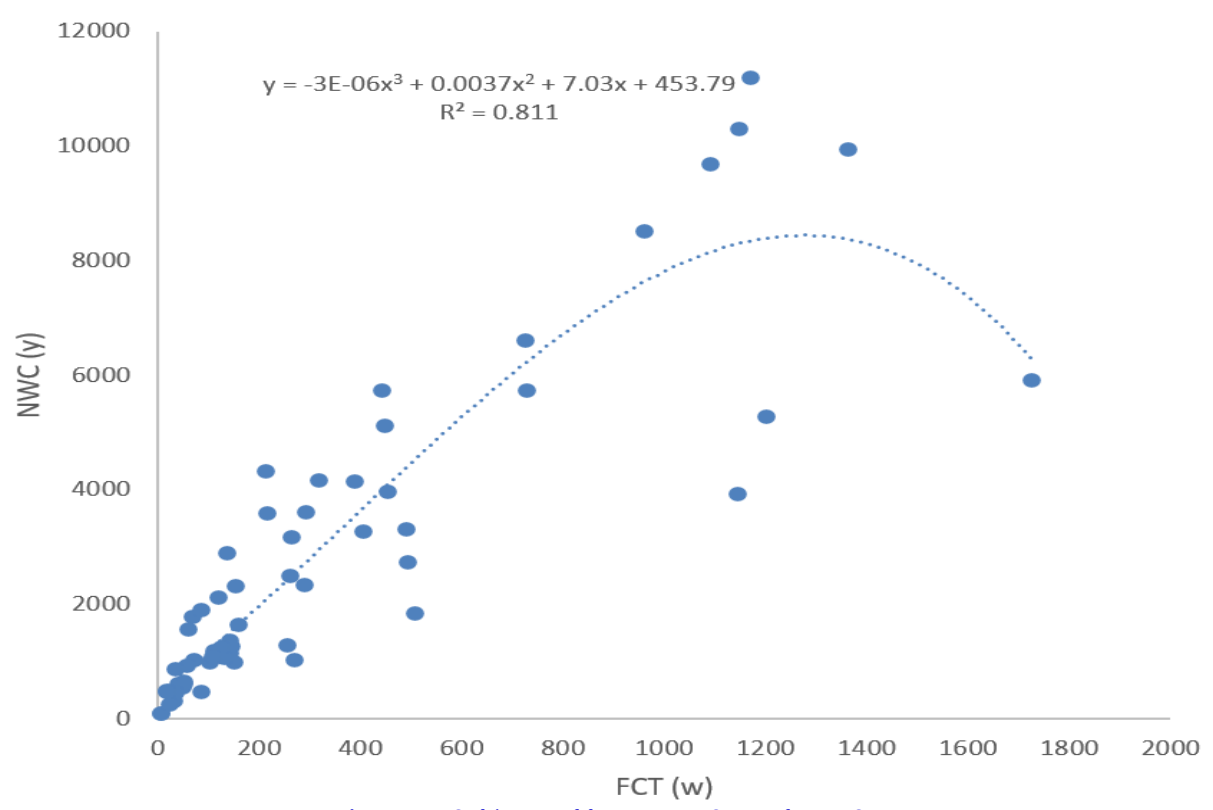

Figure 3. Cubic trend between FCT and NWC.

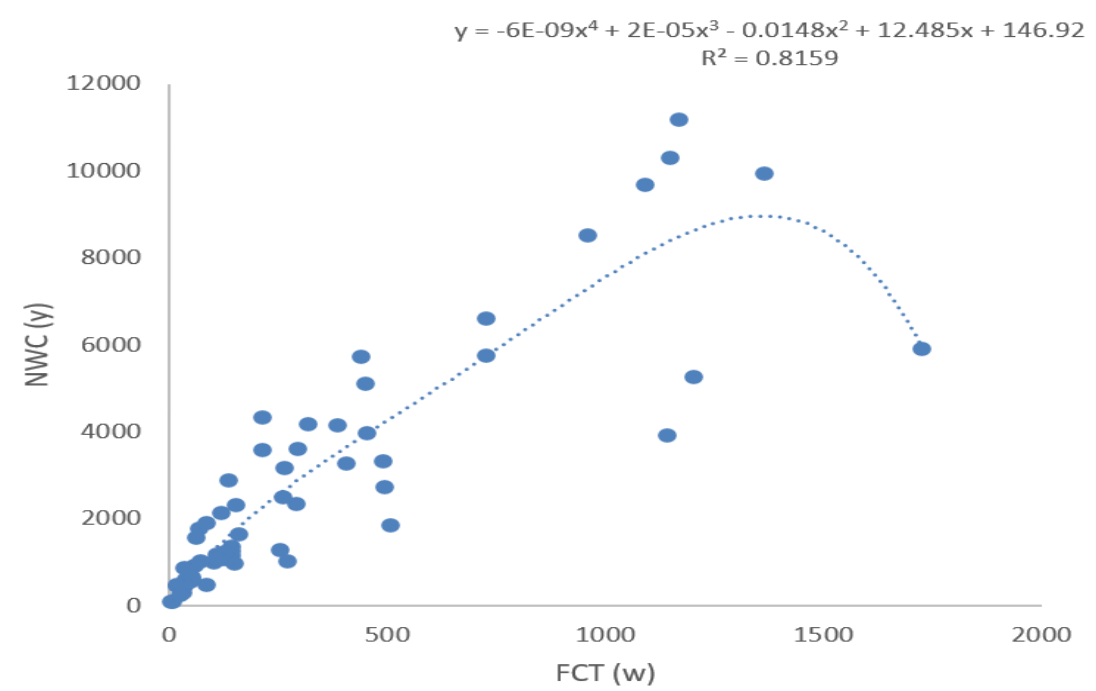

Figure 4. Quartic trend between FCT and NWC. 
Table 3. Trend analysis of NNWC (y) against LAGOS (w)

\begin{tabular}{|c|c|c|c|c|}
\hline Coefficients & Linear & Quadratic & Cubic & Quartic \\
\hline$\beta_{0}$ & $482.51(0.003)^{* *}$ & $-181.48(0.352)$ & $-63.19(0.810)$ & $-86.91(0.80)$ \\
\hline$\beta_{1}$ & $2.356(0.000) * *$ & $3.713(0.000) * *$ & $3.263(0.000)^{* *}$ & $3.38(0.011) * *$ \\
\hline$\beta_{2}$ & & $-3.10 \times 10^{-4}(0.000) * *$ & $1.41 \times 10^{-5}(0.977)$ & $-1.3 \times 10^{-4}(0.925)$ \\
\hline$\beta_{3}$ & & & $-5.123 \times 10^{-8}(0.503)$ & $2.49 \times 10^{-8}(0.996)$ \\
\hline$\beta_{4}$ & & & & $-6.248 \times 10^{-12}(0.911)$ \\
\hline$R^{2}$ & $89.5 \%$ & $92.5 \%$ & $92.5 \%$ & $92.5 \%$ \\
\hline $\bar{R}^{2}$ & $89.4 \%$ & $92.2 \%$ & $92.1 \%$ & $92.0 \%$ \\
\hline $\begin{array}{l}\text { Analysis of } \\
\text { Variance }\end{array}$ & $\begin{array}{lc}\text { Source } & \text { P-Value } \\
\text { Regression } & 0.000^{* *} \\
\text { LAGOS x } & 0.000^{*} *\end{array}$ & $\begin{array}{lr}\text { Source } & \text { P-Value } \\
\text { Regression } & \text { O.OOO** } \\
\text { LAGOS x } & \text { O.OOO** }^{*} \\
\mathrm{x}^{2} & 0.000^{* *}\end{array}$ & $\begin{array}{lc}\text { Source } & \text { P-Value } \\
\text { Regression } & 0.000^{*} * \\
\text { LAGOS x } & 0.000^{* *} \\
\mathrm{x}^{2} & 0.977 \\
\mathrm{x}^{3} & 0.503\end{array}$ & $\begin{array}{lc}\text { Source } & \text { P-Value } \\
\text { Regression } & 0.000^{*} * \\
\text { LAGOS x } & 0.011^{* *} \\
\mathrm{x}^{2} & 0.925 \\
\mathrm{x}^{3} & 0.996 \\
\mathrm{x}^{4} & 0.911\end{array}$ \\
\hline
\end{tabular}

The results in Table 3 and Figures $5-8$ identified that the quadratic trend is the best trend among the trend curves to describe Covid-19 Pandemic in LAGOS against the National weekly confirmed cases. The R-square value indicates that the predictors explain $92.5 \%$ of the variance of the Covid-19 Pandemic. This suggests that a quadratic trend is more appropriate. The quadratic trend does not appear to be over fit and has adequate predictive ability.

The identified trend is: $\quad \mathrm{Y}_{t}=C_{0}+C_{1} X_{t}+C_{2} X_{t}^{2}=-181 .+3.713 X_{t}-\left(3.10 \times 10^{-4}\right) X_{t}^{2}$

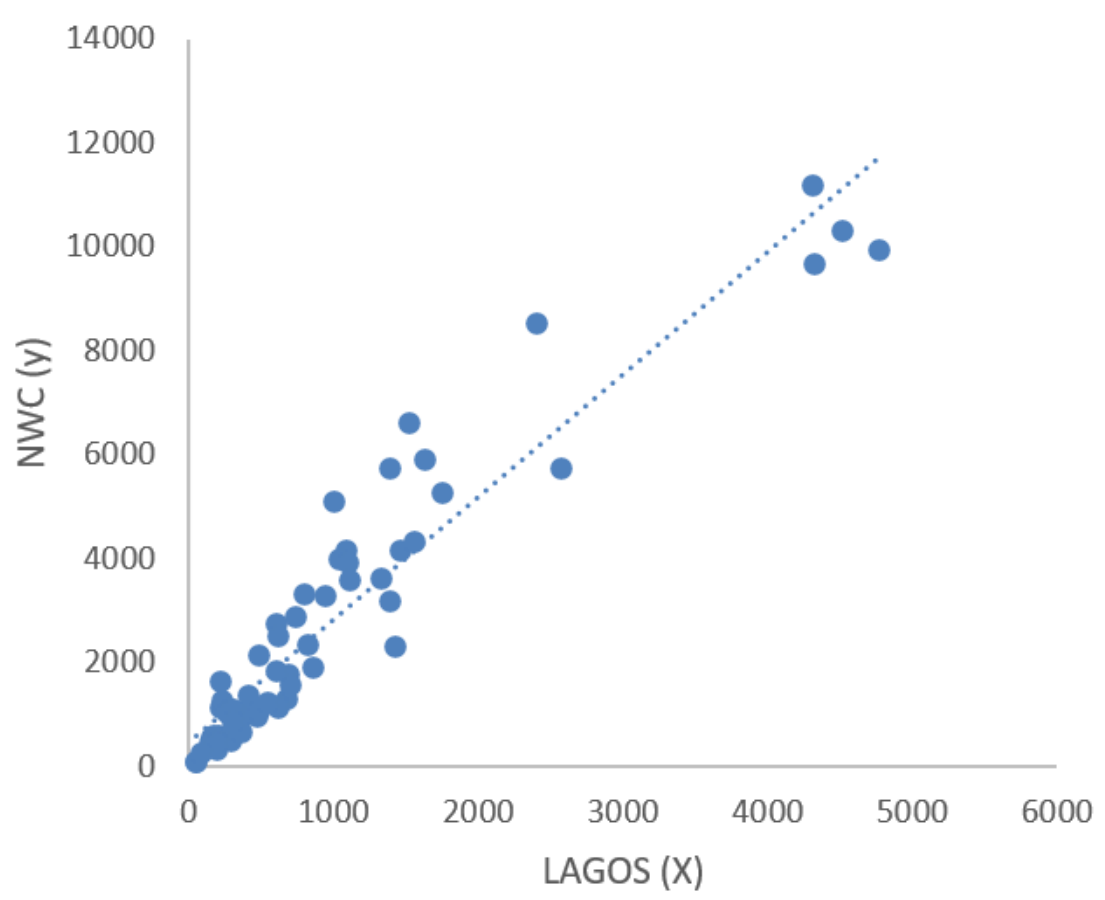

Figure 5. Linear trend between Lagos and NWC. 


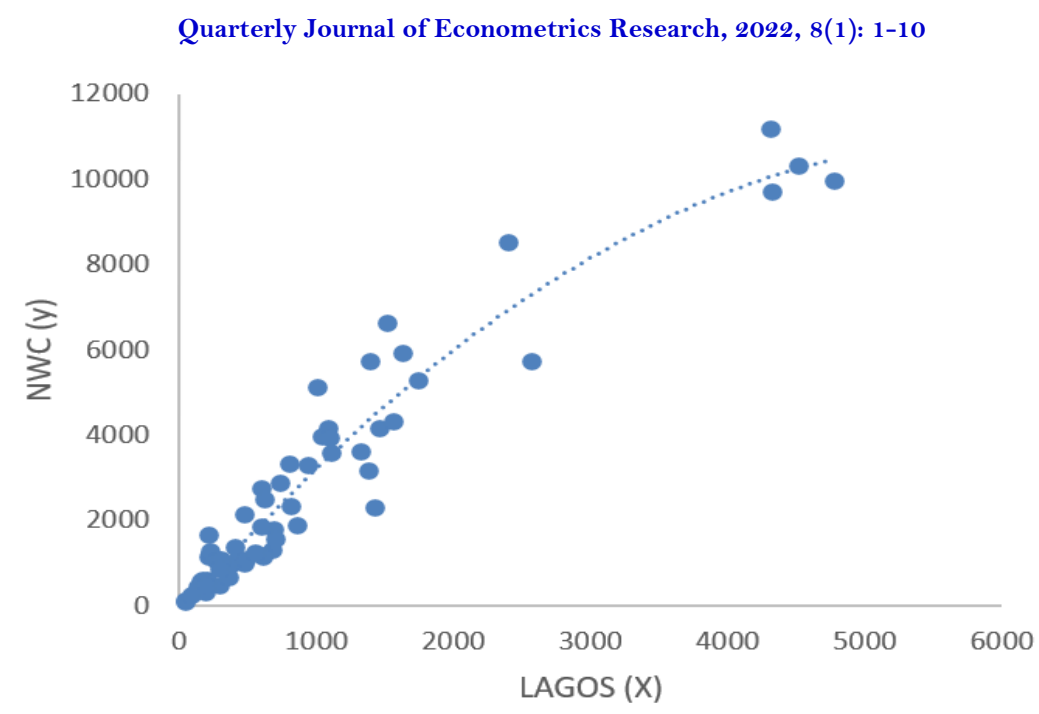

Figure 6. Quadratic trend between Lagos and NWC.

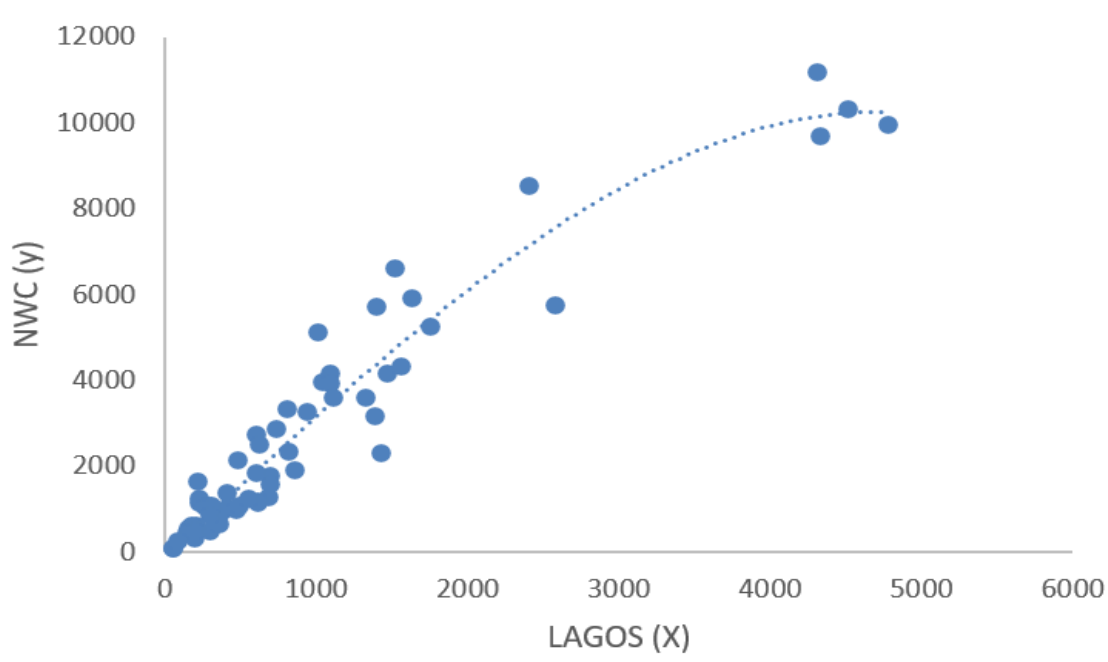

Figure 7. Cubic trend between Lagos and NWC.

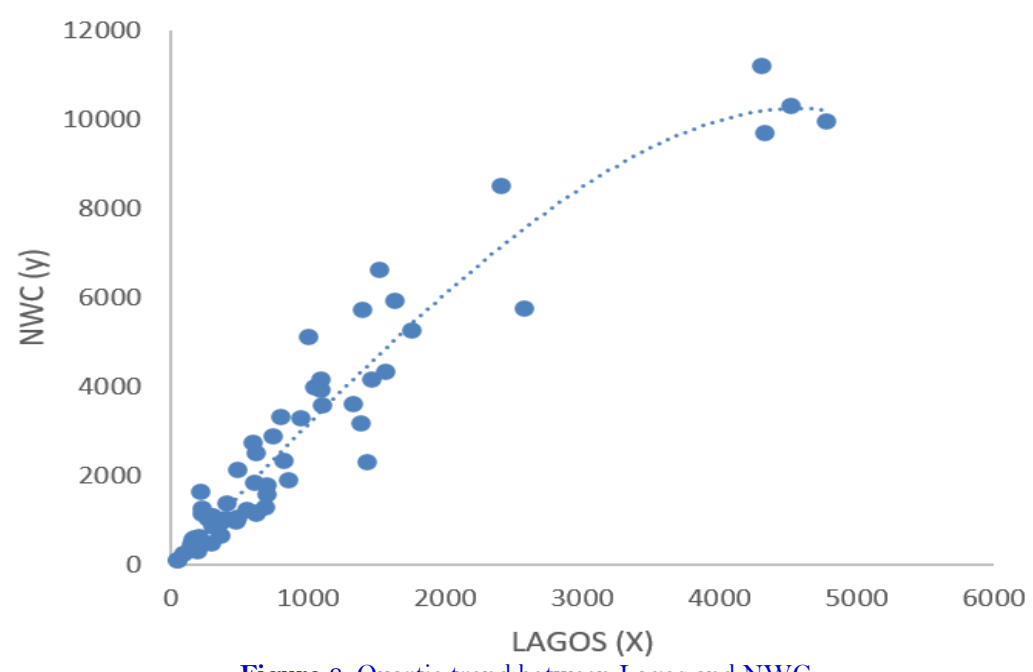

Figure 8. Quartic trend between Lagos and NWC.

\subsection{GARCH Model}

Three GARCH models were built to the COVID 19 pandemic FCT and Lagos against the Nigeria National weekly confirmed case, which are $\operatorname{ARCH}(1)$ or $\operatorname{GARCH}(0,1)$; $\operatorname{GARCH}(1,0)$ and $\operatorname{GARCH}(1,1)$. The summarized result is in Table 4. 
Table 4. GARCH (p,q) models parameter estimate and selection criteria values for FCT against the national weekly confirmed case

\begin{tabular}{|c|c|c|c|c|}
\hline Variable & Model & $\begin{array}{l}\text { Parameter Estimate } \\
\text { (p-values) }\end{array}$ & Selection Criteria & Remark Suitable Model \\
\hline$\overline{\operatorname{FCT}}\left(\nabla w_{t}\right)$ & $\begin{array}{l}\text { GARCH }(1,1) \\
\text { With constant }\end{array}$ & $\begin{array}{l}\hat{\mu}=347.413\left(0.00251^{* *}\right) \\
\alpha_{0}=123014\left(0.06893^{*}\right) \\
\alpha_{1}=0.758674\left(0.00453^{*}\right) \\
\beta_{2}=0.241326(0.11860)\end{array}$ & $\begin{array}{l}\mathrm{AIC}=999.2664 \\
\mathrm{HQC}=1004.182 \\
\mathrm{LKH}=493.6532 \\
\mathrm{SCW}=1011.832\end{array}$ & Not suitable \\
\hline $\operatorname{FCT}\left(\nabla w_{t}\right)$ & $\begin{array}{l}\text { GARCH }(0,1) \\
\text { With constant }\end{array}$ & $\begin{array}{l}\hat{\mu}=312.973\left(0.00868^{* *}\right) \\
\alpha_{0}=300765\left(0.00840^{* *}\right) \\
\alpha_{1}=1\left(0.00430^{* *}\right)\end{array}$ & $\begin{array}{l}\mathrm{AIC}=999.7568 \\
\mathrm{HQC}=1003.853 \\
\mathrm{LKH}=-494.8784 \\
\mathrm{SCW}=1010.229\end{array}$ & $\begin{array}{l}\text { GARCH }(0,1) \text { is } \\
\text { Most suitable }\end{array}$ \\
\hline $\operatorname{FCT}\left(\nabla w_{t}\right)$ & $\begin{array}{l}\text { GARCH }(1,0) \\
\text { With constant }\end{array}$ & $\begin{array}{l}\hat{\mu}=347.413\left(0.00251^{* *}\right) \\
\alpha_{0}=123014\left(0.06893^{* *}\right) \\
\alpha_{1}=0.758674\left(0.00453^{* *}\right) \\
\beta_{2}=0.241326(0.11860)\end{array}$ & $\begin{array}{l}\mathrm{AIC}=999.2664 \\
\mathrm{HQC}=1004.182 \\
\mathrm{LKH}=-493.6332 \\
\mathrm{SCW}=1011.832\end{array}$ & Not suitable \\
\hline
\end{tabular}

From the Table 4, the identified GARCH model is GARCH $(\mathrm{O}, 1)$, since all its parameters are significant at $5 \%$ and $10 \%$ also two of its model selection criteria are smaller than the other two GARCH models.

Table 5. GARCH (p,q) Models parameter estimate and selection criteria values for LAGOS against the national weekly confirmed case.

\begin{tabular}{|c|c|c|c|c|}
\hline Variable & Model & $\begin{array}{l}\text { Parameter Estimate } \\
\text { (p-values) }\end{array}$ & Selection Criteria & $\begin{array}{l}\text { Remark } \\
\text { Suitable Model }\end{array}$ \\
\hline $\operatorname{Lagos}\left(\nabla w_{t}\right)$ & $\begin{array}{l}\text { GARCH }(1,1) \\
\text { With constant }\end{array}$ & $\begin{array}{l}\hat{\mu}=58.0152(0.45922) \\
\alpha_{0}=77236.5(0.18789) \\
\alpha_{1}=0.783045\left(0.03635^{* *}\right) \\
\beta_{1}=0.216955(0.14515)\end{array}$ & $\begin{array}{l}\mathrm{AIC}=971.7802 \\
\mathrm{HAQ}=976.6955 \\
\mathrm{LKH}=-479.8901 \\
\mathrm{SCW}=984.3463\end{array}$ & $\overline{\text { Not Suitable }}$ \\
\hline $\operatorname{Lagos}\left(\nabla w_{t}\right)$ & $\operatorname{GARCH}(0,1)$ & - & - & Not Suitable \\
\hline $\operatorname{Lagos}\left(\nabla w_{t}\right)$ & $\begin{array}{l}\text { GARCH }(1,0) \\
\text { Without } \\
\text { constant }\end{array}$ & $\begin{array}{l}\hat{\mu}=\mathrm{NILL} \\
\alpha_{0}=65622.2\left(0.00001^{* *}\right) \\
\alpha_{1}=0.77876\left(0.01017^{* *}\right) \\
\beta_{1}=0.22124\left(0.09431^{*}\right)\end{array}$ & $\begin{array}{l}\mathrm{AIC}=970.7934 \\
\mathrm{HAQ}=974.8894 \\
\mathrm{LKH}=-480.3967 \\
\mathrm{SCW}=981.2651\end{array}$ & $\begin{array}{l}\text { GARCH }(1,0) \\
\text { Without constant } \\
\text { is most suitable }\end{array}$ \\
\hline
\end{tabular}

From the Table 5, the identified GARCH model is GARCH (1,0), since all its parameters are significant at 5\% and $10 \%$ and all its model selection criteria are smaller better than the other GARCH model.

\subsubsection{Comparison of the Identified GARCH Model of the Two AREA}

We compare the two identified GARCH model in the two areas to determine the model that has more effect on National weekly confirmed cases in Table 6.

Table 6. GARCH (p,q) models parameter estimate and selection criteria values between FCT/LAGOS against the national weekly confirmed cases.

\begin{tabular}{|c|c|c|c|c|}
\hline Variable & Model & Parameter Estimate (p-values) & Selection Criteria & Remark \\
\hline $\operatorname{LAGOS}\left(\nabla x_{t}\right)$ & $\begin{array}{l}\text { GARCH }(1,0) \\
\text { without } \\
\text { constant }\end{array}$ & $\begin{array}{c}\hat{\mu}=\mathrm{NILL} \\
\alpha_{0}=65622.2\left(0.00001^{* *}\right) \\
\alpha_{1}=0.77876\left(0.01017^{* *}\right) \\
\beta_{1}=0.22124\left(0.09431^{*}\right)\end{array}$ & $\begin{array}{c}\mathrm{AIC}=970.7934 \\
\mathrm{HQC}=974.8894 \\
\mathrm{LKH}=-480.3967 \\
\mathrm{SCW}=981.2651\end{array}$ & $\begin{array}{c}\text { GARCH }(1,0) \\
\text { Is more } \\
\text { suitable }\end{array}$ \\
\hline
\end{tabular}


Table 6 show that GARCH model with the highest effect on Nigeria National weekly confirmed cases is $\operatorname{GARCH}(1,0)$ for LAGOS, since all its parameters are significant at $5 \%$ and $10 \%$ and all its model selection criteria are smaller better than of FCT GARCH model (GARCH $(0,1)$.

\section{SUMMARY AND CONCLUSION}

The trend analysis and GARCH model on covid-19 pandemic spread between FCT/Lagos and the National Weekly confirmed pandemic cases were carried out using the Minitab17 software and Gretl. The Figures 1 to 8 show the linear, quadratic, cubic and quartic trends for both FCT and Lagos, Tables 2 to 4 show the analysis of the GARCH models. However, this study has established the quadratic trend and the Lagos GARCH $(1,0)$ as the best model that describes the data. GARCH $(0,1)$, GARCH $(1,0)$ and GARCH $(1,1)$ were built separately for both FCT and Lagos to determine which one was best for the weekly reported cases of covid-19 pandemic in those areas. GARCH $(0,1)$ was identified as the best of the three (3) models built for FCT weekly confirmed cases. While GARCH $(1,0)$ was identified for Lagos weekly pandemic confirmed cases. Comparing the two models; $\operatorname{GARCH}(0,1)$ of FCT and GARCH(1,0) of Lagos, considering the model selection criteria (AIB,BIC,HQC and LKH)and parameter estimates (p-values), GARCH $(1,0)$ was found to be better. This implies that the effects of the number of pandemic cases confirmed will be more on Lagos.

Funding: This study received no specific financial support.

Competing Interests: The authors declare that they have no competing interests.

Authors' Contributions: All authors contributed equally to the conception and design of the study.

\section{REFERENCES}

Abdulmajeed, K., Adeleke, M., \& Popoola, L. (2020). Online forecasting of covid-19 cases in Nigeria using limited data. Journal of Science Direct, 30, 105683.Available at: https://doi.org/10.1016/j.dib.2020.105683.

Aronu, C. O., Ekwueme, G. O., Sol-Akubude, V. I., \& Okafor, P. N. (2021). Coronavirus (COVID-19) in Nigeria: Survival rate. Scientific African, 11, e00689.Available at: https://doi.org/10.1016/j.sciaf.2020.e00689.

Awan, T., \& Aslam, M. F. (2020). Prediction of daily covid-19 cases in European countries using automatic ARIMA model. Journal of Public Health Research, 9(3), 1765.Available at: https://doi.org/10.4081/jphr.2020.1765.

Malki, Z., Atlam, E.-S., Ewis, A., Dagnew, G., Alzighaibi, A. R., ELmarhomy, G., . . . Gad, I. (2021). ARIMA models for predicting the end of COVID-19 pandemic and the risk of second rebound. Neural Computing and Applications, 33(7), 2929-2948.Available at: https://doi.org/10.1007/s00521-020-05434-0.

Odukoya, O., Adejimi, A., Isikekpe, B., Jim, C., Osibogun, A., \& Ogunsola, F. (2020). Epidemological trends of corona virus disease 2019 in Nigeria. Nigeria Postgraduate Medical Journal, $27(40)$, 271-279.

Onafeso, O. D., Onafeso, T. E., Olumuyiwa-Oluwabiyi, G. T., Faniyi, M. O., Olusola, A. O., Dina, A. O., .. . Adagbasa, E. (202 1). Geographical trend analysis of COVID-19 pandemic onset in Africa. Social Sciences E Humanities Open, 4(1), 100137.

Rauf, R. I., \& Oladipo , H. O. (2020). Forecasting the spread of covid-19 in Nigeria using box-Jerking Modeling Procedure, the Journal of.Available at: https://doi.org/10.1101/2020.05.05.20091686.

Views and opinions expressed in this article are the views and opinions of the author(s), Quarterly Journal of Econometrics Research shall not be responsible or answerable for any loss, damage or liability etc. caused in relation to/arising out of the use of the content. 